\title{
EFFECT OF INJECTION HOLE DIAMETER ON OPERATIONAL CONDITIONS OF COMMON-RAIL FUEL-INJECTION SYSTEM FOR PORT- INJECTION HYDROGEN-FUELED ENGINE
}

\author{
Mohammed Kamil ${ }^{1}$ and M.M. Rahman ${ }^{2,3 *}$ \\ ${ }^{1}$ Faculty of Engineering, University of Tikrit, Tikrit, Iraq \\ ${ }^{2}$ Faculty of Mechanical Engineering, University of Malaysia Pahang \\ 26600 Pekan, Pahang, Malaysia \\ *E-mail: mustafizur@ump.edu.my \\ Phone: +(6)-094246239, Fax: +(6)-09-4246222 \\ ${ }^{3}$ Automotive Engineering Centre, University of Malaysia Pahang \\ 26600 Pekan, Pahang, Malaysia.
}

\begin{abstract}
Modeling of the hydrogen-fueled engine injection system is a very important tool that can be used to explain or predict the effect of advanced injection strategies on combustion and emissions. This work proposes a common-rail (CR) injection system for a four-stroke four-cylinder hydrogen-fueled engine with a port-injection feeding system. A numerical one-dimensional gas dynamic model was developed considering a single injection event for each injector per cycle. For this purpose, one-dimensional flow equations in conservation form are used to simulate wave propagation phenomena throughout the CR (accumulator). The effect of the CR on the injection-system characteristics has been clarified. These characteristics include: rail pressure, sound velocity, rail mass flow rate, injected mass flow rate and pressure drop across injectors. The interaction effects of operational conditions (engine speed and rail pressure) and geometrical features (injector hole diameter) are illustrated. The required compromise solutions are highlighted. The $\mathrm{CR}$ injection system is shown to be a promising enhancement for the port-injection hydrogen-fueled engine.
\end{abstract}

Keywords: Hydrogen Engine, port injection, common rail, injection hole diameter, engine speed.

\section{INTRODUCTION}

Hydrogen has been considered as both a renewable and a sustainable fuel [1]. The major automobile manufacturers, such as General Motors, Ford, Chrysler, Diamler-Benz, BMW, Toyota, Honda and Mazda among others, announced that they would start marketing hydrogen-fueled cars in the first decade of the $21^{\text {st }}$ century [2-5]. However, it is not expected that this promise will come true in the near future due to the unique fact that the hydrogen route still faces vast challenges and the dawn of hydrogen as a fuel demands more and more effort and sacrifice. Many multifarious topics ask for follow up research and development $(\mathrm{R} \& \mathrm{D})$. Hydrogen cannot be collected by mining and harvesting; instead, it has to be manufactured, usually either by electrolysis or steam reformation of natural gas [6]. Then, it has unique combustive properties, which can be beneficial under certain engine operating conditions and pose technical challenges under other engine operating conditions [7-10]. These challenges include abnormal 
combustion (pre-ignition, backfiring and knocking) [11], and higher heat transfer losses [12]. Furthermore, hydrogen's usefulness as an energy carrier is also reduced by its low energy content on a volume basis, limiting onboard storage. It can be stored as a gas, a cryogenic liquid, or, in addition, in solid-state. A particular problem with liquid hydrogen is boil off. As the liquid warms, boil-off gas is released which must be vented from the storage tank. In confined spaces there is a risk of fire or explosion if there is contact with a flame. Furthermore, contact with liquid hydrogen destroys living tissue due to its very low temperature of $-253{ }^{\circ} \mathrm{C}$ [13], so serious burning could arise from contact with hydrogen escaping from pressurized fuel systems [14]. The task of a hydrogen induction (injection) system is to meter the appropriate quantity of hydrogen for the given engine speed and load each cylinder, each cycle. Further, a hydrogen injection system should contribute to preventing abnormal combustion (pre-ignition, backfiring and knocking); and result in reasonable volumetric efficiency, thermal efficiency and power output for the whole engine. Another main responsibility of a hydrogen injection system is to reduce $\mathrm{NO}_{\mathrm{x}}$ emissions to the lowest levels. Of course, the simplicity, durability and cost are other important issues. It is difficult to develop a system that can meet all these requirements, especially with combustive properties, like these of hydrogen. In this case, compromise solutions must be adopted to achieve optimum operation and advanced technologies are demanded to overcome the obstacles.

Hydrogen can be induced to the combustion chamber either by external injection (e.g., using port or manifold fuel injection) or direct injection to the combustion chamber. Injecting hydrogen fuel directly into the cylinder is not accompanied by preignition and typically has the potential for the highest power $[15,16]$. However, it leads to a reduction in thermal efficiency due to the non-homogeneity of the mixture inside the cylinder and the required compact fuel injection system. Besides, currently available injector prototypes still do not meet the durability requirements needed for directinjection hydrogen engine applications [17]. Consequently, hydrogen induction by means of port injection (PI) can be considered as a compromise between the sophisticated direct injection system and the uncontrollable carbureted system. As a compromise solution, the PI design must approach as closely as possible the desired features and move away from the undesired. This suggests that extensive studies and enhancements must be achieved with PI.

A common rail (CR) hydrogen injection system is proposed herein to improve the performance of the PI system. The main key for this enhancement is the flexibility that can be provided for the most important injection parameters[3, 18]. Pressure level generation is almost independent of the engine speed and of fuel metering; the injection timing and duration can be optimized for every working condition. In diesel engines, the CR injection system has met with extraordinary success and is reasonable for the everincreasing share of diesel engines on the European automotive market [19]. CR electroinjectors have been thoroughly investigated by researchers in the automotive field, in order to obtain fast actuation, retaining, at the same time, good precision of the injected fuel volume [20]. However, the dynamics of CR hydraulic components can cause sensitive perturbations to multiple injections, which hence occur under different conditions from those expected. The wave propagation phenomena arising in the system, subsequent to an injection event, lead to pressure oscillations that influence the injected fuel quantity, particularly when the dwell time between consecutive injections is changed. The dependence of the injected quantity on the system dynamics for diesel engines was also highlighted by other authors [21-23]. The rail pressure is also affected by the system dynamics: Whenever an injection occurs, the pressure in the rail drops 
because the rail itself does not behave as an infinite volume capacity [24]. A sensor for continuously monitoring the pressure at the injector inlet was proposed in [25] to deliver information to the engine control unit (ECU) and thus adjust the injection parameters, so as to better control the injected fuel quantity. In fact, all these studies and findings are reported for the diesel CR injection system. It is quite difficult to find a work reporting a detailed analysis of the CR hydrogen injection system and the pressure-wave propagation phenomena in this system. Numerical models of the CR diesel injection system, based on one-dimensional (1D) partial differential equations, were developed in [20, 23, 26]. However, no models have been developed for the CR hydrogen PI system. In the present work, and for the first time in the literature, a CR hydrogen injected system is suggested and modeled for the PI hydrogen-fueled engine. A 1D compressible pipe flow model is developed using computer aided engineering software. The gas dynamic and pressure-wave propagation phenomena which take place in the CR injection system were examined briefly and its response to the variation in several parameters including the engine speed, rail pressure, and injector hole diameter, is clarified.

\section{INJECTION-SYSTEM MODELING}

A common rail injection system (CRIS) for a four-stroke four-cylinder PI hydrogen fueled engine is modeled. A numerical 1D gas dynamic model is developed considering a single injection event for one injector per cycle to simulate the wave propagation phenomena throughout the CR (accumulator). The effect of the CR's existence on the injection-system characteristics is examined, including the rail pressure, sound velocity, rail mass flow rate, injected mass flow rate and pressure drop across the injectors. In addition, the interaction effects of operational conditions (engine speed and rail pressure) and geometrical features (injector hole diameter) are demonstrated. The CRIS is proposed to improve the performance of the PI system. In diesel engines, the CRIS has achieved extraordinary success and is reasonable for the ever-increasing share of diesel engines on the European automotive market [19]. The main components of the suggested hydrogen CRIS are shown in Figure 1.

The hydrogen CRIS is modeled using the simulation code for simulating fuel injection systems. Figure 2 presents the developed CR hydrogen injection system. The temperature of the high pressure hydrogen tank is considered to be equal to the ambient temperature $(300 \mathrm{~K})$ and the composition is pure hydrogen gas. The high pressure in the tank is dealt with as a parameter. This high pressure is reduced to a pre-specified value through a pressure regulator. The regulator is modeled as an orifice connection between the tank outlet and the next tube. The diameter of the orifice was set as a parameter to control the pressure downstream of the regulator. The discharge coefficients are calculated using the geometry of the mating pipe and the orifice diameter assuming that all transitions are sharp edges. This representation is applied to the check valves and regulators in the entire system. The next part in the hydrogen line is a pipe which connects the tank with the filter. The conduction heat transfer between the pipe wall and the hydrogen gas was ignored and the initial temperature of the pipe wall is considered to be equal to the environment temperature. This selection is applied to the pipes in this system. The filter is modeled as a pipe similar to the delivery pipe. However, higher surface roughness is assumed in order to consider the pressure losses in this part. Another two pipes are added to simulate hydrogen lines. Three flexible pipes are also included upstream of the rail to investigate the effect of the elasticity of these pipes on 
the hydrogen wave speed. The function of the check valve in the hydrogen line is to ensure that hydrogen flow takes place in one direction and that no reverse flow occurs.

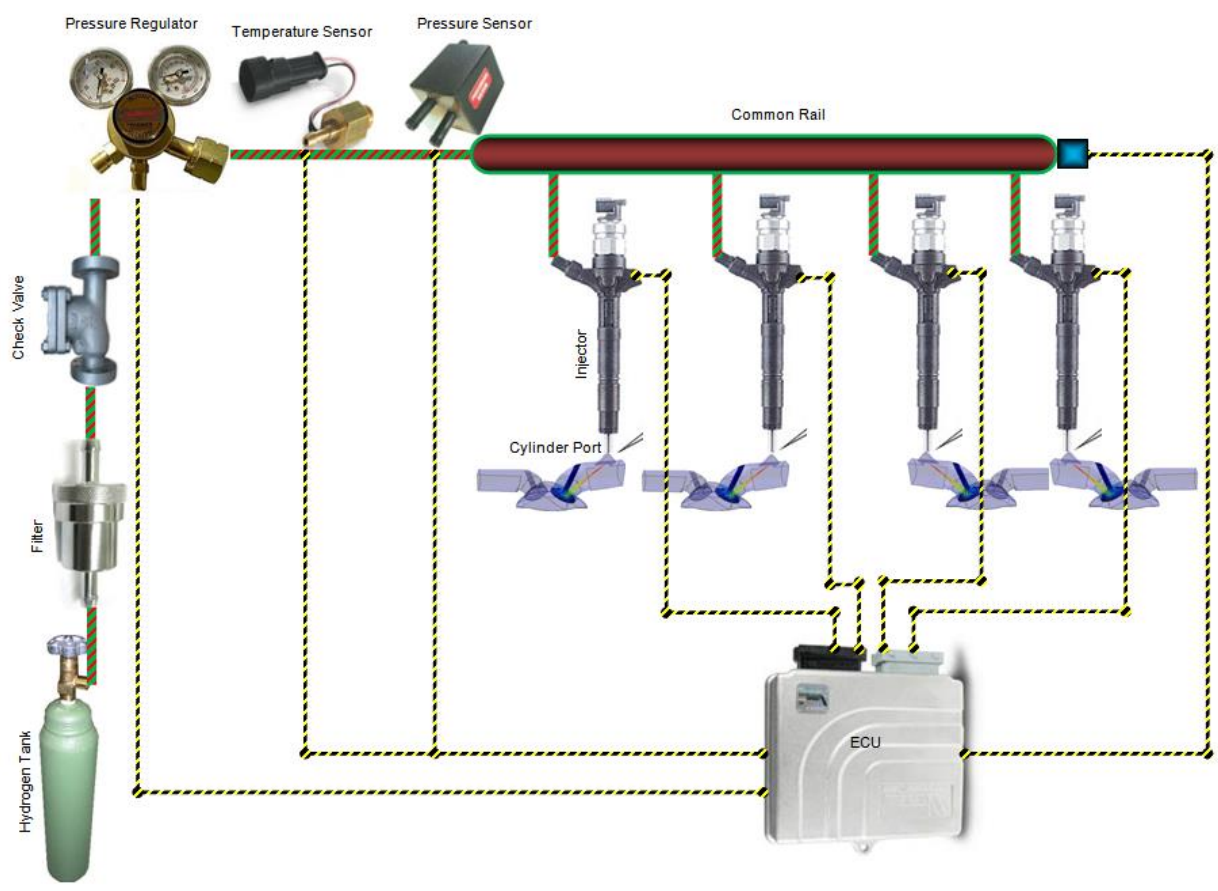

Figure 1. CR hydrogen injection system.

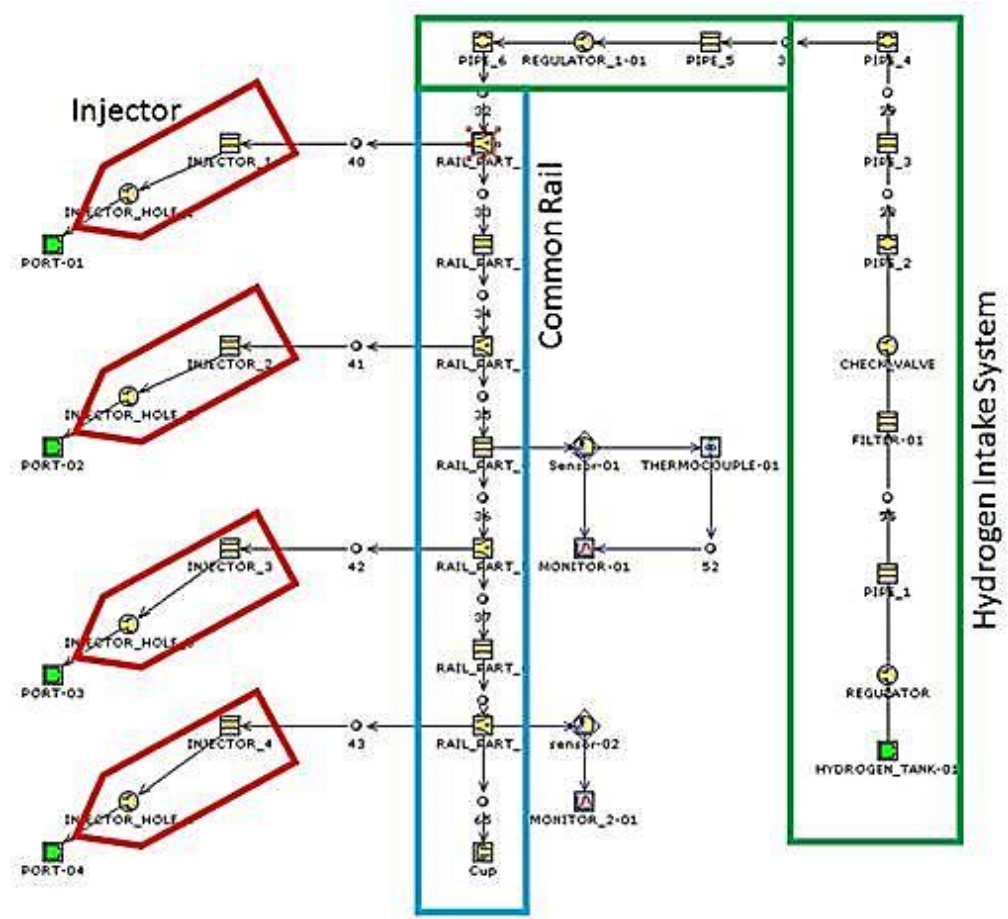

Figure 2. Model set-up for the hydrogen CRIS.

The rail has the task of storing hydrogen and damping out the pressure fluctuations as effectively as possible. Figure 3 shows the configuration of the CR which is modeled using a series of pipes and flow-splits. It is composed of four flow- 
splits connected by three pipes. The flow-splits consist of an intake and two discharges. The intake draws hydrogen fuel from the preceding flow component (pipe). One discharge supplies hydrogen to the next pipe and the other supplies hydrogen to the injector. The last discharge of the last flow-split is closed. The characteristic length and expansion diameter are defined for each port in the flow-split. The characteristic length is the distance from the port plane to the opposite side of the flow-split (used in calculating the propagation of pressure waves through the flow-split). The expansion diameter is the diameter into which the flow expands from the port diameter upon entering the flow-split (used in calculating the kinetic energy losses due to area expansion inside the flow-split). Figure 4 shows the detailed geometry of flow-split no. 1. Sensors and monitors are equipped in the rail to sense and monitor the variations in pressure and temperature with the crank angle throughout the simulation. They are fixed in flow-split no. 4 and pipe no. 2, respectively. The fuel injector events (opening and closing) are prescribed instead of being calculated. The opening and closing profiles of the injectors are imposed using pipes and orifices to model the injectors. The pipe represents the piping inside the injector and the orifice represents the injector holes. The opening and closing of the injector is controlled through the orifice diameter. The orifice diameter is defined as a function of the main drive (crank shaft) angle. This simplification is made because the focus here is on the gas dynamic phenomena in the CR. Each injector is assumed to have four holes. The diameters of the holes are considered to be parameters in investigating their effects on the flow.

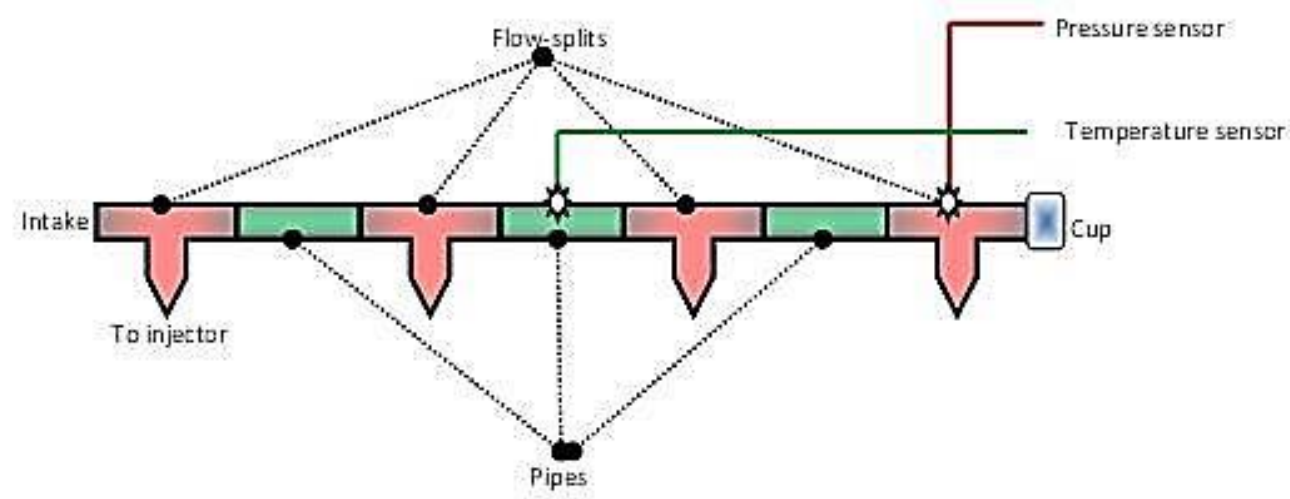

Figure 3. CR configuration.

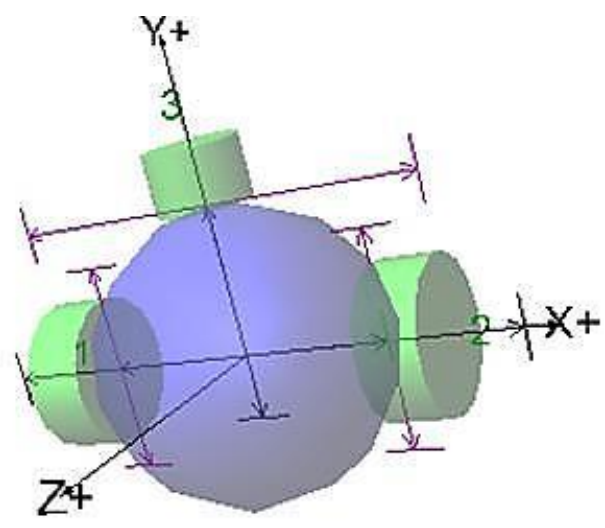

Figure 4. Geometry of the flow-split. 


\section{RESULTS AND DISCUSSION}

The wave propagation and gas dynamic behavior of hydrogen gas flow in a four-stroke four-cylinder PI hydrogen-fueled engine are investigated in this section. The effects of engine speed, and injector hole diameter are considered.

\section{Influence of Engine Speed}

The flow in the CR is unsteady due to the opening and closing of the periodic injectors. The opening and closing of the injectors create finite amplitude compression and rarefaction pressure waves that propagate through the hydrogen flow in the CR. These pressure waves may aid or inhibit the hydrogen exchange processes. Therefore, the size of the CR is tuned properly to achieve the best gas exchange. Namely, pressure waves aid the exchange process. The effect of engine speed on the gas dynamic of the hydrogen flow is investigated with a speed range of $3000-5000 \mathrm{rpm}$ for a $0.5 \mathrm{~mm}$ injector hole diameter and 3 bar rail pressure.

Figure 5 shows the trends of the different parameters in the CRIS with engine speed. The rail pressure, speed of sound, mass flow rate, injectors mass flow rate, and pressure drop across the injectors are the considered parameters. The pressure variation in the CR with the crank angle for the considered engine speeds is shown in Figure 5(a). The complexity of the phenomena that occur is apparent. The amplitude of pressure fluctuations increases substantially with a decrease in engine speed. Maximum amplitude of $0.043 \mathrm{bar}$ was recorded at $5000 \mathrm{rpm}$, while the maximum amplitude of 0.0325 bar was at $3000 \mathrm{rpm}$. However, frequency of the pressure waves is the same for the different speeds. The rapid closing of the injectors results in high-oscillation waves known as the "hammer effect" which is clearly seen in Figure 5(a). To explain this behavior, assume that the valve (orifice) in the injector is open and a flow in the injector pipe is induced. There is an initial pressure $p_{0}$ and an initial velocity $v$ in the pipe as shown in Figure 6(a). Suddenly, the orifice is closed, which creates a pressure wave that travels toward the main rail. Hydrogen gas between the wave and the orifice is at rest but the gas between the wave and the rail still has the initial velocity $v$ (Figure 6(b)). When the wave reaches the main rail the whole pipe has the pressure $p_{0}+\Delta p$, but the pressure in the rail remains at $p_{0}$. This imbalance with regard to pressure causes hydrogen to flow from the pipe back to the rail with the velocity $v$ and a new pressure wave is created which travels toward the orifice end of the pipe (Figure 6(c)). When the wave reaches the end, the gas is still flowing. The pressure at this point is less than the initial value $p_{0}-\Delta p$. This leads to a rarefied wave of pressure in the other direction (Figure $6(\mathrm{~d})$ ). When this wave reaches the rail, the pipe has a pressure again and the process repeats itself in a periodic manner (Figure 6(e)).

Higher speeds lead to higher numbers of closing and opening times for each injector and this is reflected in the higher frequency for the pressure pulsations. Each injection triggers a pressure wave in the rail. This wave influences the fuel quantity of the next injection. Flow rate differences among injectors cause differences in fuel quantity from cylinder to cylinder. The speed of sound is an important parameter for the CRIS, because the pressure waves propagate along the CR with a velocity which depends on the speed of sound. The speed of sound is the speed at which pressure waves are transmitted through the gas. The speed of sound of hydrogen at $0^{\circ} \mathrm{C}$ is equal to $1270 \mathrm{~m} / \mathrm{sec}$ compared with $331 \mathrm{~m} / \mathrm{sec}$ for air in the same condition. This big difference comes from the difference in the molar mass (2.016 for hydrogen) compared 
with 28.97 for air. This suggests that the pressure waves in hydrogen gas propagate faster in the CR.

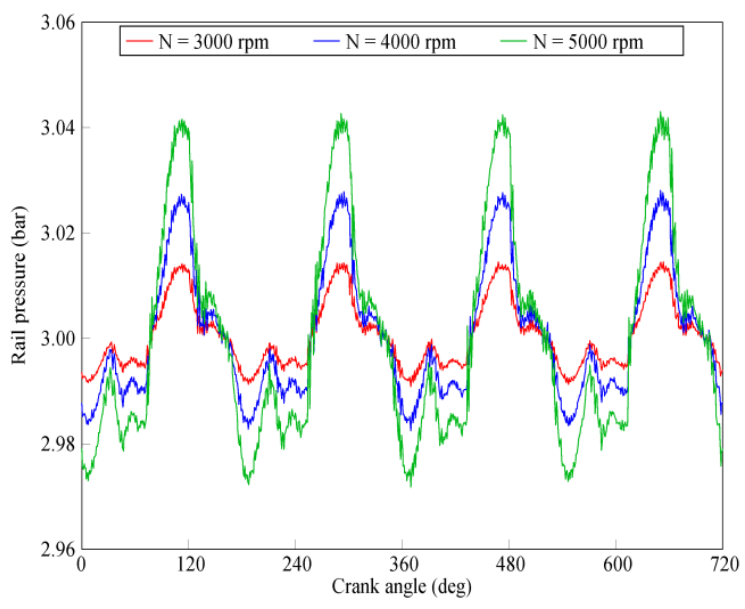

(a) Rail pressure

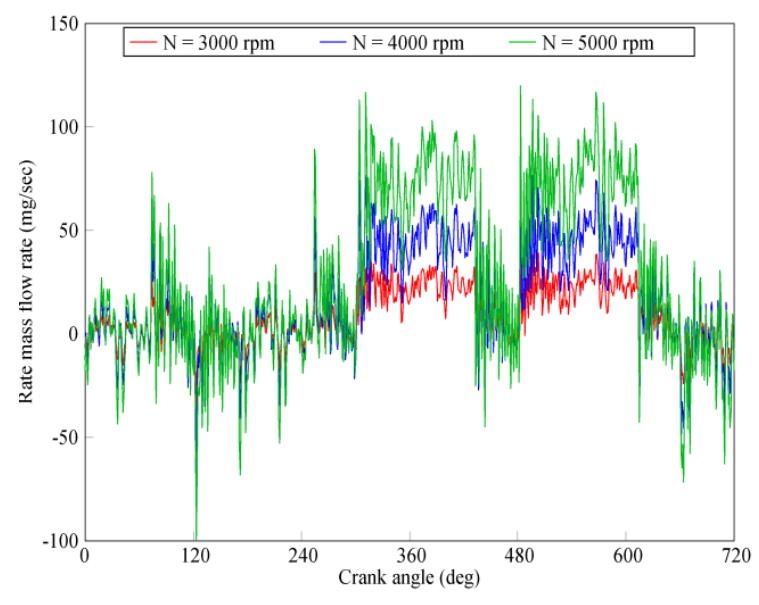

(c) Rail mass flow rate

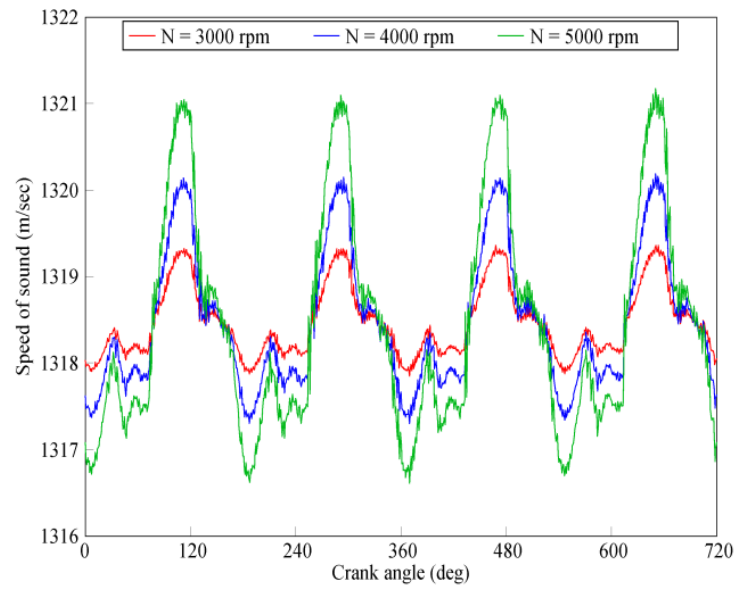

(b) Speed of sound

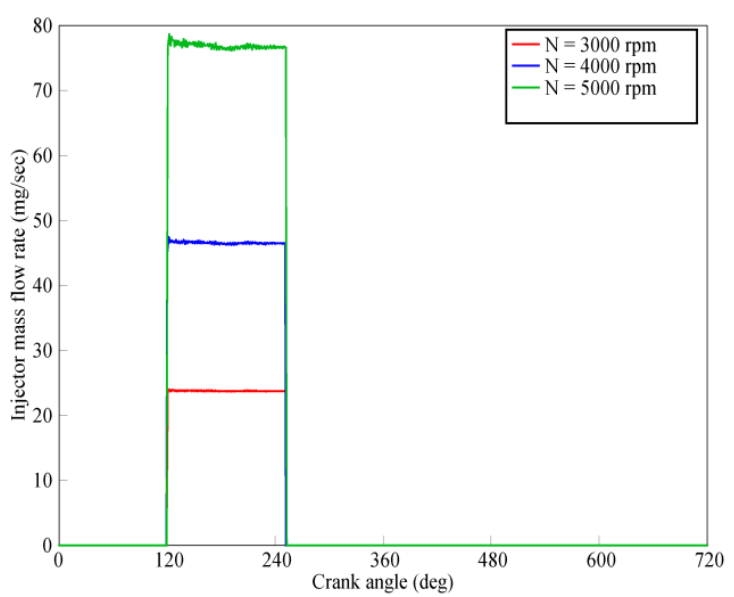

(d) Injector mass flow rate

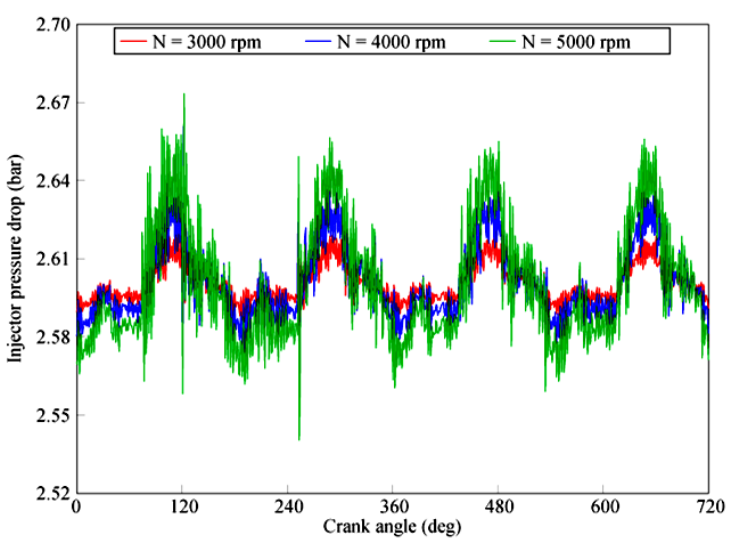

(e) Injector pressure drop

Figure 5. Trends of CR system parameters with engine speed.

Figure 5(b) demonstrates the behavior of the speed of sound in the rail for the selected speeds. The similarity between the curves in Figures 5(a-b) is very clear. This 
indicates that the pressure-wave propagation depends strongly on the speed of sound. Again, higher speeds lead to higher amplitudes but do not affect the frequencies. At $5000 \mathrm{rpm}$, the maximum speed of sound of $1321.1 \mathrm{~m} / \mathrm{sec}$ is noted, while at $3000 \mathrm{rpm}$ it is $1319.38 \mathrm{~m} / \mathrm{sec}$. In fact, the difference between the two speeds is very small compared with the value of the speed of sound. It is just $0.013 \%$ from the value of the speed of sound at $3000 \mathrm{rpm}$. This suggests that engine speed has a minor effect on the speed of sound. These minor changes are due to the changes that take place in the hydrogen's temperature and density.

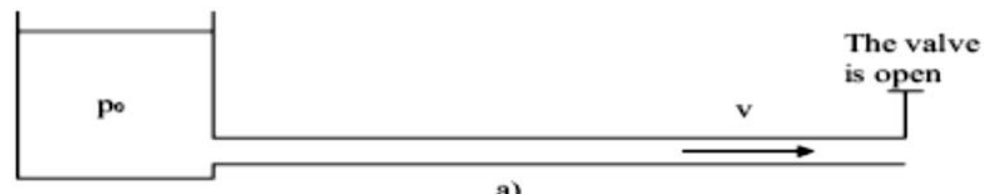

a)
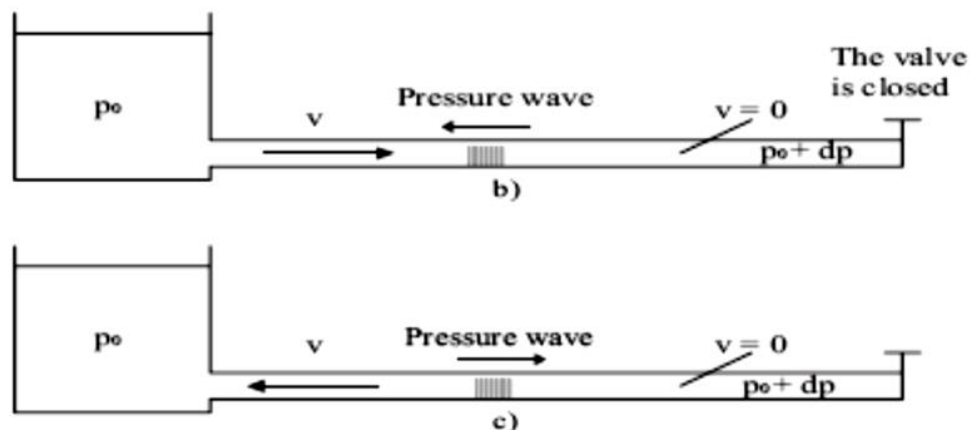

c)

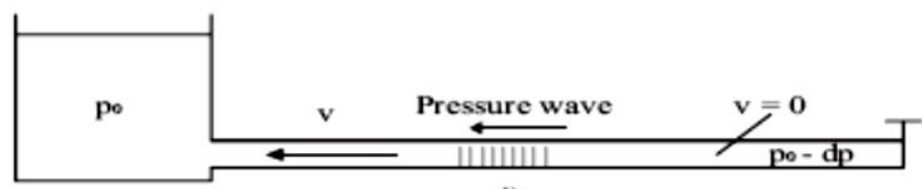

d)

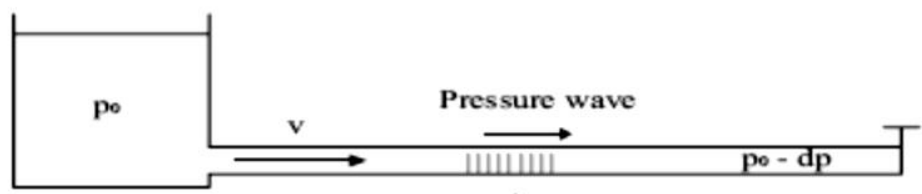

e)

Figure 6. Wave propagation mechanism [21].

In Figure 5(c), the instantaneous hydrogen mass flow rate in the crank angle domain through the CR is shown. The interaction between the three speeds curves makes distinguishing between them quite difficult. However, the higher hydrogen flow rate can be seen for $5000 \mathrm{rpm}$. The rapid closing and opening of the injectors cause high fluctuation in the mass flow rate throughout the rail. Reverse flow (negative flow out) can be seen in some parts of the cycle. The gas dynamic effects distort the CR and this led to the reverse flow which is a direct result of the pressure imbalance that occurs between the accumulator (rail) and the pipes of the injector. A maximum mass flow rate of $122 \mathrm{mg} / \mathrm{sec}$ is reported at $5000 \mathrm{rpm}$. Figure 5(d) shows the measured mass flow rate through the injector orifice. It shows clearly the influence of the oscillations in rail pressure on the injection rate. The main parameters that affect the injected mass flow rate are the discharge coefficient, orifice diameter, and density of the fuel, as well as the difference between the hydrogen pressure at the orifice exit and the port pressure. Hence, pressure fluctuations across the injector orifice lead to these fluctuations in the 
injected mass. The value of the injector hole discharge coefficient is essential for accurate modeling of the injected mass flow rate. The injector hole discharge coefficient is considered to be 0.765 for this study. Higher mass flow rates can be seen for higher speeds. The mass flow rate fluctuations occur in very small amplitudes (maxima of 0.5 $\mathrm{mg} / \mathrm{sec}$ at $5000 \mathrm{rpm}$ and $0.344 \mathrm{mg} / \mathrm{sec}$ at $3000 \mathrm{rpm}$ ), with high frequencies.

\section{Effect of Injector Hole Diameter}

Engine speed is related to the operational condition of the engine and was discussed in the previous section. The trends with the dimensions of the injection system, which are a physical feature, will be presented in the following section. As illustrated in Figure 2, each injector was assumed to have four holes; however, the diameters are the equivalence diameters of a one-hole orifice by conserving the total flow area (for example, a flow area for a $5 \mathrm{~mm}$ hole diameter [Area $=\pi \times(5)^{2}$ ] is equivalent to the flow area for 4 holes each $2.5(5 / 2) \mathrm{mm}$ in diameter [thus Area $=4 \times \pi \times(5 / 2)^{2}$ ]. Three equivalence diameters of 5,7 and $9 \mathrm{~mm}$ are investigated. In other words: three injectors were investigated; each with four holes. The diameters of these holes were 2.5 (5/2), $3.5(7 / 2)$ and $4.5(9 / 2) \mathrm{mm}$. Engine speed and rail pressure were kept constant at $3000 \mathrm{rpm}$ and $3 \mathrm{bar}$, respectively. This engine speed is an intermediate value in the speed range.

Figure 7 shows the influence of the injector hole diameter on the selected parameters of the CRIS. The trends in the rail pressure throughout the engine cycle are shown in Figure 7(a). Clearly, high amplitude is seen for larger diameters. The waves seem to be in phase because the speed of the engine is kept constant. Figure 7(b) plots the speed of sound for the different injector hole diameters. The fluctuations in these curves are in phase with those of Figure 7(a). Higher amplitudes occur with larger injector hole diameters. Maximum speeds of $1321.4 \mathrm{~m} / \mathrm{sec}$ and $1319 \mathrm{~m} / \mathrm{sec}$ are obtained for the injector hole diameters of 0.9 and $0.5 \mathrm{~mm}$, respectively. The variation in the speed of sound is negligible $(0.02 \%)$. Figure $7(\mathrm{c})$ demonstrates the response of the injected mass flow rate to the variations in the injector hole size. This is shown to be substantial when compared with the responses to engine speed. As explained in the discussion of Figure 5(d), the injector hole diameter is a main parameter in determining the injected mass flow rate. The hole diameter has a major impact on the injected mass flow rate. The value of the diameter is selected during the design stage because it is difficult to change. Figure 7(d) illustrates the effect of the injector hole diameter on the mass flow rate in the rail. Greater flow rates are obtained with larger holes. The interaction between the curves here is less in comparison with that seen in Figure 5(c). An inverse flow happens for the three cases. This may be due to high pressure fluctuation which takes place after the injection event. This wave distorts the flow strongly and causes the reverse flow. This behavior can be seen for all the curves presented in the present study. Figure 7(e) shows the pressure drop across the injector orifice as it varies with the hole diameter. It is worth pointing out that the present model was developed considering single injection events (not multi injection). The fluctuation in the pressure drop across the injector that is shown in the figure affects the injected mass for each injector. This leads to cyclic variation and unstable operation. As stated previously, the pressure drop is an important factor in determining the injected mass and any abnormality in this drop is reflected directly in the injected mass. 


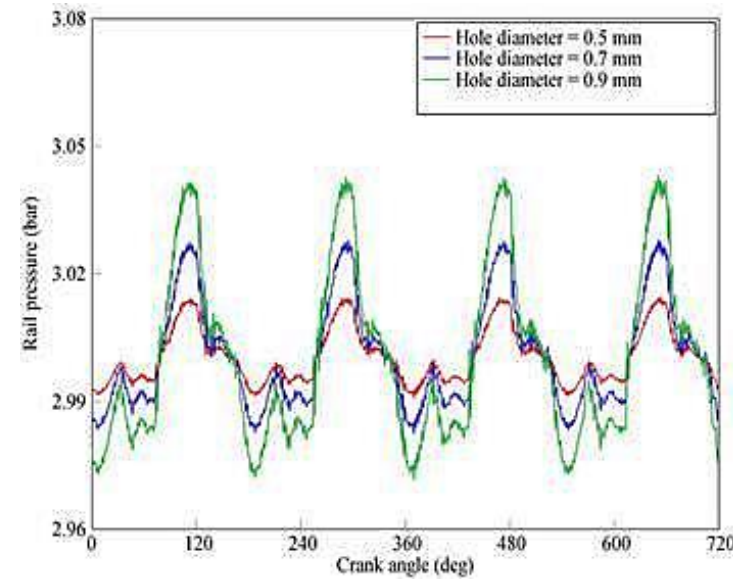

(a) Rail pressure

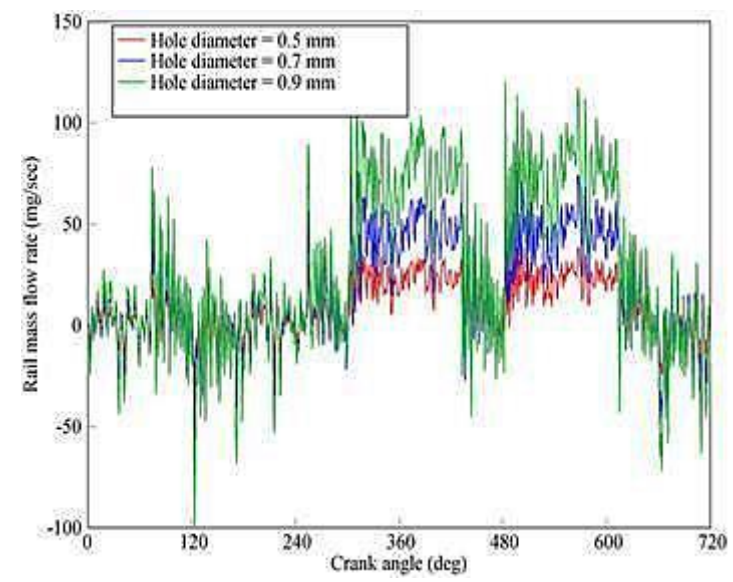

(c) Rail mass flow rate

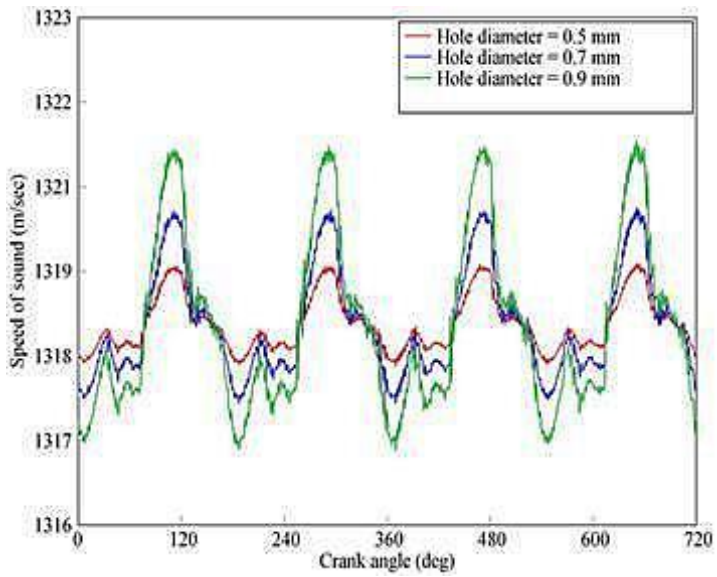

(b) Speed of sound

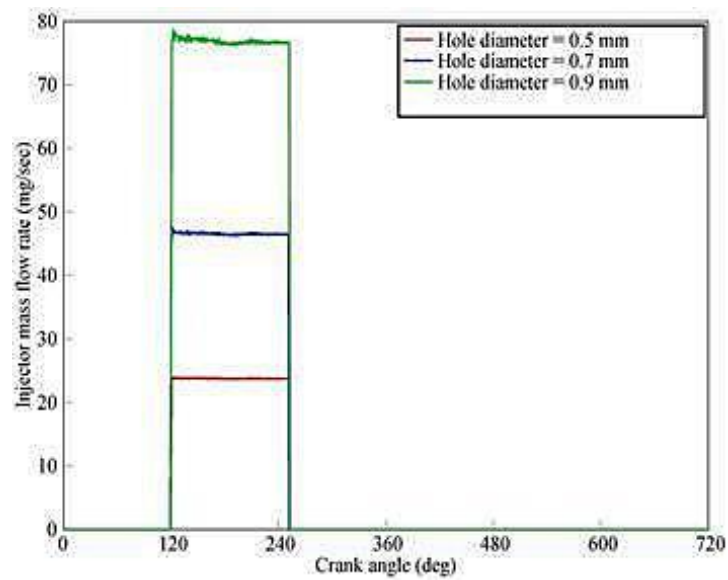

(d) Injector mass flow rate

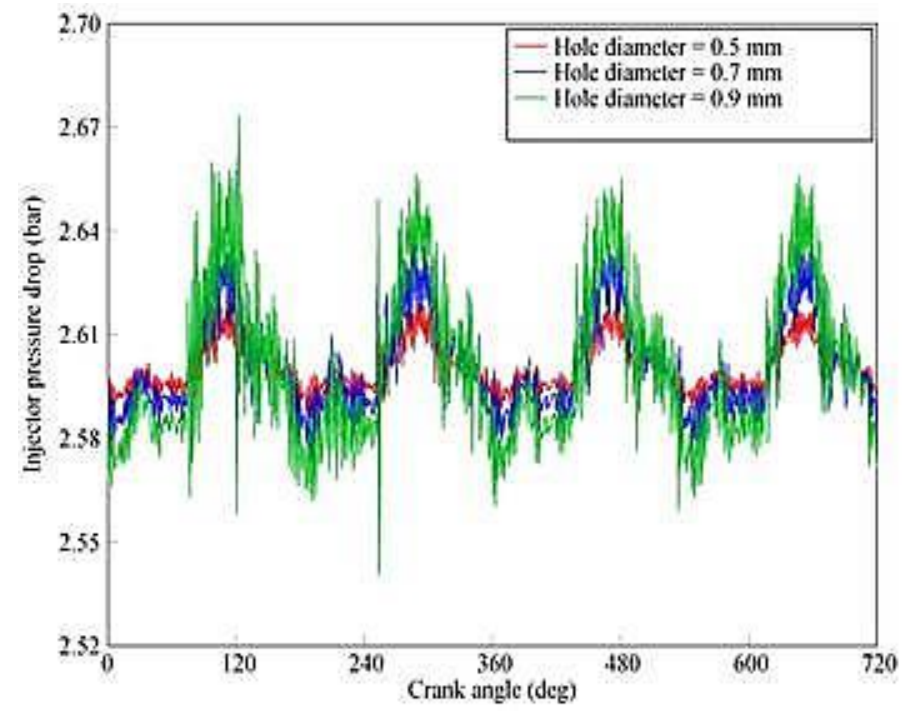

(e) Injector pressure drop

Figure 7. Trends of CR system parameters with hole diameter. 


\section{CONCLUSIONS}

A numerical investigation of the dynamics of a single injection event CR hydrogeninjection-system was undertaken. The highly unsteady wave propagation phenomena taking place in the system play a major role in the proper understanding of important injection-system characteristics. In order to obtain a deeper insight into the cause and effect relationship between the injection-triggered pressure-oscillation and the injectionsystem layout, an effective 1D numerical model was proposed. From the analysis of the system behavior with different operational and geometrical parameters, the following conclusions are drawn:

i) The proposed CRIS for the hydrogen engine can play a dramatic role in developing the PI hydrogen engine; similar to the extraordinary success of the CRIS in the diesel engine. The CR system is responsible for the ever-increasing share (so far 40\%) of diesel engines in the European automotive market.

ii) Although low pressures (2-4 bar) have been investigated for the PI system, the gas dynamic and pressure propagation phenomena for hydrogen gas fuel are still effective and have a major effect on the performance of the CRIS.

iii) The tuning process must take into account the engine's operating conditions (engine speed), the injection-system's operating condition (rail pressure), and the geometrical characteristics (like the injector hole diameter).

iv) The hydrogen-gas-fueled CRIS is considerably simpler than the standard dieselfueled injection system. This is because the fuel is stored at high pressures in a cylinder fuel tank and there is no need for a high-pressure pump. However, the high sound velocity for hydrogen leads to higher propagation speed pressure oscillations.

\section{ACKNOWLEDGMENT}

The authors would like to express their gratitude to Universiti Malaysia Pahang (UMP) for providing laboratory facilities and support.

\section{REFERENCES}

[1] Midilli A, Dincer I. Hydrogen as a renewable and sustainable solution in reducing global fossil fuel consumption. International Journal of Hydrogen Energy. 2008;33:4209-22.

[2] Veziroglu TN. Dawn of the hydrogen age. International Journal of Hydrogen Energy. 1998;12:1077-8.

[3] Kamil M, Rahman MM, Bakar RA, Kadirgama K. Modeling of SI engine for duel fuels of hydrogen, gasoline and methane with port injection feeding system. Energy Education Science and Technology Part A: Energy Science and Research. 2012;29:1399-416.

[4] Hamada KI, Rahman MM, Aziz ARA. Parametric study of instantaneous heat transfer based on multidimensional model in direct-injection hydrogen-fueled engine. International Journal of Hydrogen Energy. 2013;38:12465-80. 
[5] Rahman MM, Hamada KI, A. Aziz AR. Characterization of the time-averaged overall heat transfer in a direct-injection hydrogen-fueled engine. International Journal of Hydrogen Energy. 2013;38:4816-30.

[6] Crabtree GW, Dresselhaus MS, Buchanan MV. The hydrogen economy. Physics Today. 2004;57:39-44.

[7] Verhelst S, Sierens R, Verstraeten S. A critical review of experimental research on hydrogen fueled SI engines. SAE Technical Paper No. 2006-01-0430; 2006.

[8] Kamil M, Rahman MM, Bakar RA. Integrated simulation model for composition and properties of gases in hydrogen fueled engine. International Journal of Automotive and Mechanical Engineering. 2013;8:1242-155.

[9] Kamil M, Rahman MM, Bakar RA. An integrated model for predicting engine friction losses in internal combustion engines. International Journal of Automotive and Mechanical Engineering. 2014;9:1695-708.

[10] Kamil M, Rahman MM, Bakar RA. Performance evaluation of external mixture formation strategy in hydrogen fueled engine. Journal of Mechanical Engineering and Sciences. 2011;1:87-98.

[11] White C, Steeper R, Lutz A. The hydrogen-fueled internal combustion engine: a technical review. International Journal of Hydrogen Energy. 2006;31:1292-305.

[12] Shudo T. Improving thermal efficiency by reducing cooling losses in hydrogen combustion engines. International Journal of Hydrogen Energy. 2007;32:428593.

[13] Verhelst S, Wallner T. Hydrogen-fueled internal combustion engines. Progress in Energy and Combustion Science. 2009;35:490-527.

[14] MacLean HL, Lave LB. Evaluating automobile fuel/propulsion system technologies. Progress in Energy and Combustion Science. 2003;29:1-69.

[15] Mohammed SE, Baharom M, Aziz ARA. Analysis of engine characteristics and emissions fueled by in-situ mixing of small amount of hydrogen in CNG. International Journal of Hydrogen Energy. 2011;36:4029-37.

[16] Rahman MM, Kamil M, Bakar RA. Engine performance and optimum injection timing for 4-cylinder direct injection hydrogen fueled engine. Simulation Modelling Practice and Theory. 2011;19:734-51.

[17] Welch A, Mumford D, Munshi S, Holbery J, Boyer B, Younkins M, et al. Challenges in developing hydrogen direct injection technology for internal combustion engines. SAE Technical Paper No. 2008-01-2379; 2008.

[18] Kamil M, Rahman MM, Bakar RA. Modeling of common rail fuel injection system of four cylinder hydrogen fueled engine. Journal of Engineering and Technology. 2010;1:42-52.

[19] Catania AE, Ferrari A, Manno M, Spessa E. Experimental investigation of dynamics effects on multiple-injection common rail system performance. Journal of Engineering for Gas Turbines and Power. 2008;130:032806.

[20] Catania AE, Ferrari A, Manno M. Development and application of a complete multijet common-rail injection-system mathematical model for hydrodynamic analysis and diagnostics. Journal of Engineering for Gas Turbines and Power. 2008;130:062809.

[21] Bianchi GM, Falfari S, Pelloni P, Filicori F, Milani M. A numerical and experimental study towards possible improvements of common rail injectors. SAE Technical Paper NO. 2002-01-0500; 2002. 
[22] Henein NA, Lai M-C, Singh I, Zhong L, Han J. Characteristics of a common rail diesel injection system under pilot and post injection modes. SAE Technical Paper NO. 2002-01-0218; 2002.

[23] Catalano LA, Tondolo V, Dadone A. Dynamic rise of pressure in the commonrail fuel injection system. SAE Technical Paper No. 2002-01-0210; 2002.

[24] Mulemane A, Han J-S, Lu P-H, Yoon S-J, Lai M-C. Modeling dynamic behavior of diesel fuel injection systems. SAE Technical Paper No. 2004-010536; 2004.

[25] Torkzadeh DD, Kiencke U, Keppler M. Introduction of a new non-invasive pressure sensor for common-rail systems. SAE Technical Paper NO. 2002-010842; 2002.

[26] Ferguson R, Kirkpatrick A. Internal combustion engines-applied thermodynamic. Wiley, New York; 1986. 